\title{
Ocular Manifestations Encountered in Albinos Living in Libreville: Epidemiological and Clinical Aspects
}

\section{Prudence Ada Assoumou1,2*, Andy Viola Dohvoma ${ }^{3}$, Steve Mvogo Ebana3 ${ }^{3}$, Tatiana Mba Aki1,2, Olele Ossavou Assomo² ${ }^{2}$, Emmanuel Mve Mengome ${ }^{1,4}$, Côme Ebana Mvogo ${ }^{3}$}

\author{
${ }^{1}$ Department of Ophthalmology, Faculty of Medicine, University of Health and Science, Libreville, Gabon \\ ${ }^{2}$ Ophthalmology Department of Agondje University Hospital Center, Libreville, Gabon \\ ${ }^{3}$ Faculty of Medicine and Biomedical Sciences, University of Yaounde I, Yaounde, Cameroon \\ ${ }^{4}$ Omar Bongo Ondimba Army Instructions Hospital, Libreville, Gabon \\ Email: *prudence_apa@yahoo.fr
}

How to cite this paper: Assoumou, P.A., Dohvoma, A.V., Ebana, S.M., Aki, T.M., Assomo, O.O., Mengome, E.M. and Mvogo, C.E. (2019) Ocular Manifestations Encountered in Albinos Living in Libreville: Epidemiological and Clinical Aspects. Open Journal of Ophthalmology, 9, 203-213. https://doi.org/10.4236/ojoph.2019.94022

Received: October 5, 2019

Accepted: November 16, 2019

Published: November 19, 2019

Copyright $\odot 2019$ by author(s) and Scientific Research Publishing Inc. This work is licensed under the Creative Commons Attribution International License (CC BY 4.0).

http://creativecommons.org/licenses/by/4.0/

\begin{abstract}
Introduction: Albinism is a rare hereditary genetic disorder, characterized by melanogenesis disorders associated to varying degrees of cutaneous, atrial and visual disorders. In Libreville, no data on the subject is available. Purpose: To describe the ocular manifestations found in albinos living in Libreville. Patients and methods: This was a cross-sectional and descriptive study that took place in Libreville during a year from and that concerned 43 albinos. The inclusion criteria were any albino with oculocutaneous albinism present in Libreville who has agreed to participate in the investigation. The variables studied were age, sex, visual acuity, ametropia, iris color, iris transillumination, strabismus, nystagmus, torticollis, amblyopia, optic disc, photophobia, foveal hypoplasia and retinal hypopigmentation. Data was collected and analyzed using Epi info ${ }^{\mathrm{TM}}$ 7.2.0.1 CDC and IBM ${ }^{\circledR}$ SPSS $^{\circledR}$ V21 Statistic software. Results: The mean age was $21.2 \pm 17$ years with a (F/M) ratio of 0.53 . Visual acuity by far without correction $\left(\mathrm{AVLC}_{\mathrm{SC}}\right)<3 / 10$ was found in $88.4 \%$ of cases. Astigmatism, two-tone iris and torticollis were found respectively in $52.7 \%, 51 \%$ and $26 \%$ of cases. Retinal hypopigmentation and foveal hypoplasia were noted in $65.1 \%$ and $86 \%$ of cases. Divergent strabismus was noted in $71.4 \%$ and small and pale papilla in $95.1 \%$ of cases. Photophobia, iris transillumination, nystagmus and amblyopia were noted in $100 \%$ of cases. Conclusion: The ocular manifestations encountered in our series are similar to those described in literatures.
\end{abstract}

\section{Keywords}

Albinism, Nystagmus, Strabismus, Amblyopia, Torticollis, Photophobia, Libreville 


\section{Introduction}

Albinism is a group of hereditary disorders linked to a melanin biosynthesis abnormality, a pigment developed in the specialized cells of the skin, hair, iris, pigmented epithelium of the retina, the skin and internal ear, associated with a number and normal structure of melanocytes [1]. Albinism is a universal condition, the most common hereditary generalized hypopigmentation whose global incidence in all forms varies from $1 / 17,000$ to $1 / 20,000$ births [2] [3]. This is a clinically and genetically heterogeneous pathology with three major forms including Oculocutaneous albinism, Ocular albinism and Syndromic albinism. This condition varies from one form to another and from one continent to another with oculocutaneous albinism type 2 (OCA2) recognized as the most common form worldwide [1]. In America, its frequency for the entire population is about 1/36,000 compared to that of African-Americans with an incidence of 1/12,000 [4] and the Africans especially in Niger where it can reach 1/1000 [5]. Albinism Oculocutaneous type 1 (OCA1) uncommon among African blacks and African-Americans is more common among Caucasians. The type of Oculocutaneous albinism type 3 (OCA3) has mainly been described in Black-African and African-American with two cases reported among Caucasians. However, Oculocutaneous albinism type 4 (OCA4) remains the most common form of tyrosinase positive OCA in Japan [5]. In sub-Saharan Africa, in studies conducted in Cameroon, the hospital prevalence of albinism Oculocutaneous type 2 is 0 , $15 \%$ according to Ebana [6] and 1.15\% according to Kassir [7]. However, despite the explanations of science, albinism remains an anomaly source of fear and anxiety in Africa where albinos, victims of many prejudices are discriminated against, marginalized, forced to drop out of school and suffer physical and moral violence or even murdered for their organs, which are sold at high prices. As a result, they are confronted with a whole range of problems that constitute a hindrance to their personal growth, their school attendance, their social and professional integration and their medical care. Despite its frequency and the importance of the medical problems encountered, ocular involvement related to albinism, which is constant and serious, remains unknown in the albino subject living in Libreville in view of the only study made in 1872 [8]. Hence the initiation of this preliminary work in order to study the ocular manifestations encountered in albinos living in Libreville.

\section{Patients and Method}

This was a descriptive cross-sectional study that took place in Libreville in the Ophthalmology Department of the Angondjé University Hospital and within a private structure of the place during the period of February 1, 2017 to February 1, 2018. The study population consisted of 43 albinos with Oculocutaneous albinism identified after albino sensitization in the albino welfare association (ALBA). The inclusion criteria concerned all albinos with oculocutaneous albinism living in Libreville and having agreed to participate in the study. Exclusion 
criteria were imposed on albinos with no oculocutaneous albinism or who did not live in Libreville or who refused to participate in the survery. Consultation of each albino was made after albumin sensitization by the ALBA association. The patients listed were seen in a defined order of passage based on their availability and enthusiasm to participate in the survey. They were examined free of charge by the same medical team after obtaining their informed consent. The variables studied were age, sex, visual acuity, ametropia, iris color, iris transillumination, strabismus, nystagmus, torticollis, amblyopia, optic disc, photophobia, foveal hypoplasia and retinal hypopigmentation. All collected information was collected using a data collection sheet. The purpose of the interrogation was to obtain information on the patient's age, age of onset of ocular manifestations, and sex. The study helped to look for a torticollis by monitoring the fixation and supplemented or completed by the study of the oculomotricity in search of a strabismus and nystagmus. The ophthalmological examination, which was adapted to the patient's age, first included the study of visual acuity for each eye, then binocular, with and without correction. The visual acuity from a distance was made at a distance of 5 meters in the standard consultation room with the Monoyer Chart and the Snellen's E eye chart. The patients with visual acuity between 8/10 and 10/10 were considered emmetropic and those with visual acuity below 8/10 ametropic. Amblyopia was defined for any visual acuity less than $3 / 10$. Close visual acuity was assessed using the Parinaud or Rossano Weiss reading scale placed $33 \mathrm{~cm}$ from the patient, which was considered good between P10 and P3 and bad if less than P3. All the ametropic patients benefited from an objective refraction with the aid of an automatic refractometer after instillation of a cycloplegic essentially atropine eye drops in our series according to two protocols. In children according to the age, we instilled in both eyes a drop of atropine $1 \%, 0.5 \%$ or $0.3 \%$ morning and evening for 7 days and in adults, a drop of tropicamide alternately every five minutes with a drop of cyclopentolate for 25 minutes. Biomicroscopy has allowed inter alia the study of iris coloration, photophobia and iris transillumination. The iris coloration was perfectly observable through the transparent cornea. However, the study of iris transillumination had required examination of the slit lamp by the application of a light source on the sclera or lower eyelid. When found, it was classified into four stages according to the morphological classification established by Dr. B. Kässmann-Kellner. Photophobia was also studied by looking at a light source. The detection of nystagmus was done in monocular and binocular vision by the fixation of an optotype in the different directions of the gaze and in convergence. It made it possible to highlight its characteristics, in particular its morphology, its direction and its intensity. Depending on the intensity, the nystagmus was weak if it was visible only with the slit lamp, then the nystagmus was so visible to the naked eye at a distance less than or equal to $3 \mathrm{~m}$ and finally the nystagmus was strong if we could see it beyond $3 \mathrm{~m}$. The strabismus was objectified by the motor assessment which allowed the study of the deviation of the angle by the 
method of corneal reflections or reflections of Hirshberg. The patient fixing a point of light in front of him to $30 \mathrm{~cm}$ and with an ophthalmoscope, we study the direction of the corneal reflection. When the reflection was centered, there was no strabismus. On the other hand, when the reflection was nasal, we had a divergent strabismus and when it was temporal, strabismus was convergent. Lastly, strabismus was vertical when the reflection was higher or lower. The intraocular pressure (IOP) measured using the Goldman ${ }^{\mathrm{TM}}$ aplanation tonometer was considered normal for values between 10 and $21 \mathrm{mmHg}$. Posterior segment examination using the ophthalmoscope after dilatation by mydriatic allowed the study of the papilla, the fovea and the retina. Papillary and retinal abnormalities for hypopigmentation were classified according to B. Kasmann's classification. The foveal reflection when present gave a normal appearance of the fovea and when absent the fovea was considered hypoplastic. All these data collected on a survey sheet were reported in an Excel file of Microsoft Office 2010. Then, the analysis was done using the software Epi info ${ }^{\mathrm{TM}}$ 7.2.0.1 CDC (Center for Disease Control and Prevention) and IBM ${ }^{\circledR}$ SPSS $^{\circledR}$ Statistic 21. It used standard descriptive analyses (mean \pm standard deviation). The Chi-2 test was used for the comparison of the proportions. The correlation was considered statistically significant for values of $\mathrm{p}<0.05$. This work was done according to the recommendations of the Helsinki Declaration of Ethics on the Use of Living Things. We obtained authorizations from the managers of the structures in which we conducted our study. Informed consent was obtained from the participants. In addition, we assured them of the confidentiality of the data collected.

\section{Results}

Our study population consisted of 43 albinos, 86 eyes. The mean age was $21.2 \pm$ 17.0 years with extremes of 8 month and 62 years and the most represented age group was 0 to 9 years in $32.6 \%$ of cases (Figure 1). Our study population consisted of 43 albinos including 15 males (34.9\%) and 28 females (65.1\%) a ratio of 0.53 . Visual acuity by far without correction to 2 eyes $\left(\mathrm{AVL}_{\mathrm{SC}}\right)<3 / 10$ was noted in $88.4 \%$ of cases. It was between $3 / 10$ and $7 / 10$ without correction to 2 eyes in $11.6 \%$ of cases (Table 1$)$. Visual acuity by far with correction to 2 eyes $\left(\mathrm{AVL}_{\mathrm{SC}}\right)<$ $3 / 10$ was noted in $73.3 \%$ of cases (Table 2). Astigmatism was the most common ametropia with $52.7 \%$ of cases in both eyes, followed by myopia in $31.1 \%$ of cases and hyperopia in $16.2 \%$ of cases in both eyes (Table 3). Amblyopia was moderate in $84.8 \%$ of cases in both eyes and deep in $11.6 \%$ of cases in both eyes (Table 4). Iris had two tones in $70 \%$ of cases. It was blue in $2 \%$ of cases, brown in $23 \%$ of cases and gray in 5 of cases. Nystagmus, iris transillumination and photophobia were noted respectively in $100 \%$ of cases. Divergence strabismus was found in $71.4 \%$ of cases followed by convergent strabismus in $19 \%$ of cases. Vertical and mixed strabismus was observed in 4.8 cases respectively (Table 5). Torticollis was found in $26 \%$ of the albinos against an absence noted in $73 \%$ of the cases. Optic disc or papilla was small and pale in $81.3 \%$ of cases with retinal 
hypopigmentation found in $65.1 \%$ and foveal hypoplasia in $86 \%$ of cases.

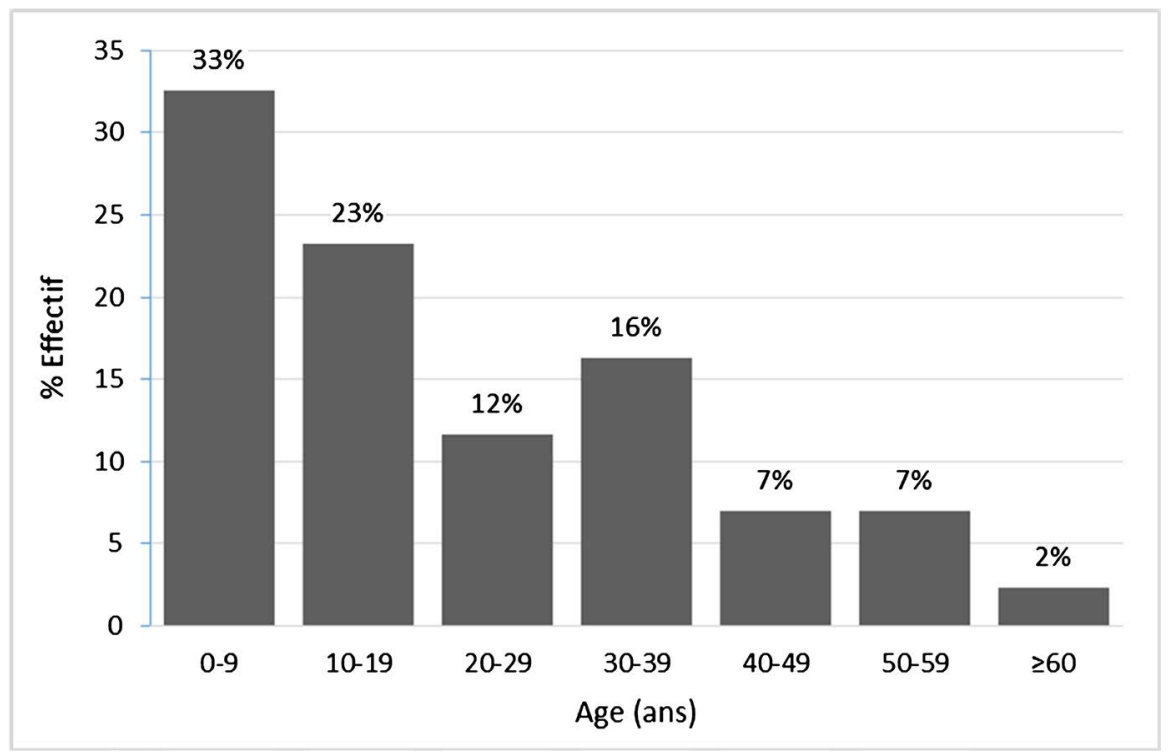

Figure 1. Distribution of albinism subjects by age group.

Table 1 . Visual acuity without correction.

\begin{tabular}{cccc}
\hline Visual Acuity Without Correction & $\begin{array}{c}\text { Right Eye } \\
\mathbf{n}(\%)\end{array}$ & $\begin{array}{c}\text { Left Eye } \\
\mathbf{n}(\%)\end{array}$ & $\begin{array}{c}\text { 2 Eyes } \\
\mathbf{n}(\%)\end{array}$ \\
\hline $8-10$ & $0(0)$ & $0(0)$ & $0(0)$ \\
$7-3$ & $5(11.6)$ & $5(11.6)$ & $10(11.6)$ \\
$<3$ & $38(88.4)$ & $38(88.4)$ & $76(88.4)$ \\
TOTAL & $43(100)$ & $43(100)$ & $86(100)$ \\
\hline
\end{tabular}

Table 2. Visual acuity with correction.

\begin{tabular}{cccc}
\hline Visual Acuity With Correction & $\begin{array}{c}\text { Right Eye } \\
\mathbf{n}(\%)\end{array}$ & $\begin{array}{c}\text { Left Eye } \\
\mathbf{n}(\%)\end{array}$ & $\begin{array}{c}\text { 2 Eyes } \\
\mathbf{n}(\%)\end{array}$ \\
\hline $8-10$ & $0(0)$ & $0(0)$ & $0(0)$ \\
$7-3$ & $10(23.3)$ & $13(30.2)$ & $23(26.7)$ \\
$<3$ & $33(76.7)$ & $30(69.8)$ & $63(73.3)$ \\
TOTAL & $43(100)$ & $43(100)$ & $86(100)$ \\
\hline
\end{tabular}

Table 3. Ametropia.

\begin{tabular}{cccc}
\hline Ametropia & $\begin{array}{c}\text { Right Eye } \\
\mathbf{n}(\%)\end{array}$ & $\begin{array}{c}\text { Left Eye } \\
\mathbf{n}(\%)\end{array}$ & $\begin{array}{c}\text { 2 Eyes } \\
\mathbf{n}(\%)\end{array}$ \\
\hline Hyperopia & $6(15.8)$ & $6(16.7)$ & $12(16.2)$ \\
Myopia & $12(31.6)$ & $11(30.6)$ & $23(31.1)$ \\
Astigmatism & $20(52.6)$ & $19(52.7)$ & $39(52.7)$ \\
TOTAL & $38(100)$ & $36(100)$ & $74(100)$ \\
\hline
\end{tabular}


Table 4. Amblyopia.

\begin{tabular}{cccc}
\hline Amblyopia & $\begin{array}{c}\text { Right Eye } \\
\mathbf{n}(\%)\end{array}$ & $\begin{array}{c}\text { Left Eye } \\
\mathbf{n}(\%)\end{array}$ & $\begin{array}{c}\text { 2 Eyes } \\
\mathbf{n}(\%)\end{array}$ \\
\hline Moderate & $25(89.3)$ & $13(86.7)$ & $38(88.4)$ \\
Deep & $3(10.7)$ & $2(13.3)$ & $5(11.6)$ \\
TOTAL & $28(100)$ & $15(100)$ & $43(100)$ \\
\hline
\end{tabular}

Table 5. Strabismus.

\begin{tabular}{cccc}
\hline Strabismus & $\begin{array}{c}\text { Right Eye } \\
\mathbf{n}(\%)\end{array}$ & $\begin{array}{c}\text { Left Eye } \\
\mathbf{n}(\%)\end{array}$ & $\begin{array}{c}\text { 2 Eyes } \\
\mathbf{n}(\%)\end{array}$ \\
\hline Convergent & $2(14.3)$ & $2(28.6)$ & $4(19)$ \\
Divergent & $11(78.6)$ & $4(57.1)$ & $15(71.4)$ \\
Vertical & $1(7.1)$ & $0(0)$ & $1(4.8)$ \\
Mixed & $0(0)$ & $1(14.3)$ & $1(4.8)$ \\
TOTAL & $14(100)$ & $7(100)$ & $21(100)$ \\
\hline
\end{tabular}

\section{Discussion}

\section{Limitations of the study}

This survey encountered several limitations, the main one being the low participation or refusal of participation of many albinos to the study despite multiple phone calls, the invitation during awareness' meetings, free ophthalmological consultations, transportation and the rapid registration for obtaining health insurance. A number of reasons based on socio-cultural beliefs that albinos would be subject to human sacrifice may explain the finding already made by some authors such as Gassama in Mali and El-Ballouti in Morocco [9] [10].

\section{Prevalence}

The study population consisted of 43 albinos or 86 eyes. The prevalence of albinism in our series was $4.24 \%$. This figure seems higher than the hospital prevalence reported by Ebana and Kassir in Cameroon in 0.15\% and 1.15\% respectively [6] [7] but remains not comparable to the figures cited because of the difference in the conditions the series was done. Indeed, our study took place at the end of an awareness period of the members of the association ALBA which indicates the non-promptness of the consultations but rather consultations motivated by being cost-free, by telephone calls, by paid transport, by the health insurance and others. The association ALBA currently has about 105 adherent albinos, if this population is related to the 850,000 inhabitants which counts Libreville, we can then estimate the prevalence of albinism in Libreville with $1.23 / 10,000$ births approximately. According to studies, the prevalence of albinism varies from one country to another and from one region to another [11] [12]. This result differs from the prevalence found by Madelain with $1 / 20,000$ and Risse with $1 / 15,000$ [13] [14]. However, the prevalence of our series is currently unusable given the lack of epidemiological data on albinism at the na- 
tional level.

\section{Age}

The average age of the population was 21.2 years with age boundaries of 8 months and 62 years. This figure is similar to that of Aboubakar [15] in Cameroon with 23.89 years and differs from those of Ajose [16] in Nigeria with 24.6 years, Gargouri [17] in Tunisia with 18 years, Ebana [6] in Cameroon with 13.11 years and Mokaya [18] in Kenya with $12.56 \pm 4.16$ years. However, this result reflects the youthfulness of the Libreville albino population which is similar to that of Aboubakar [15] in Cameroon. Nevertheless, this age remains late concerning the diagnosis and management of amblyopia, which must be done very early [6] [15]. According to studies, the life expectancy of albinos remains similar to that of the national population, but that of albinos is reduced to around 30 years because of the sacrifices and rituals they are subjected to in certain regions [9] [10].

Sex

The female population was the most represented in $65.1 \%$ of cases against $34.9 \%$ for men, a ratio of 0.5 . This result corroborates those of Aboubakar and Mokaya with respectively a sex ratio of 0.5 and 0.7 [15] [18]. On the other hand, these figures differ from those of Ebana [6], Kassir [7], Gargouri [17], and Ajose [16] who found a male-dominated ratio in respectively $1.21 ; 1.29 ; 2.1$; and 1.1. Indeed, these controversial results do not necessarily prove that albinism is a sex-related genetic disorder, but these figures can probably be justified by the strong tendency of women to participate in actions and associative life. However, this result is currently unusable because no figures were found at the national level.

\section{The ocular manifestations}

\section{Photophobia}

Photophobia is the main functional sign found in $100 \%$ of cases. This figure matches that of Mokaya [18] with $91 \%$ of cases and Ebana [6] with $100 \%$ of cases. According to the literature, photophobia is a constant symptom regardless of the regions. It can sometimes be disabling and nonspecific to Ocular cutaneous albinism because it exists in other retinal pathologies [2] and results from the reduction of secondary light filtration to melanin deficiency in all cases.

Visual acuity

In our series, the best visual acuity after correction was less than 3/10 in 73.3\% of cases. This result corroborates the better visual acuity from afar after correction found by Ebana [6] and Aboubakar [15] in Cameroon and by Mokaya [18] in Kenya. Indeed, poor visual acuity is one of the main signs associated with albinism that is present at birth and ranges from 20/40 to 20/400 births in some cases [19] [20]. According to studies, albinism is responsible for $5 \%$ to $10 \%$ of the world's low vision and this poor visual acuity related to albinism is difficult and almost impossible to improve in the majority of cases in the albino subject as reported by several authors [6] [14] [15]. However, near vision was better in our study and albino cases could see up to P2 without correction in $45.2 \%$ and 
with correction in $74.1 \%$ of cases. These results are consistent with those of other series who claim that despite the severity of low vision, near vision remains intact [21].

\section{Ametropia}

Astigmatism was the most frequently encountered ametropia in $52.7 \%$ of cases. This result represents half of Gargouri [17] with $100 \%$ of cases and of Aboubakar [15] in almost all cases. Indeed, according to studies, ametropia is constant in albinism and the most frequently encountered ametropia are strong astigmatism, medium or high hyperopia, however strong myopia is rare [2].

\section{Strabismus}

Strabismus was divergent in $71.4 \%$ of cases; this figure is different from that of Aboubakar [15] who noted it in $16.7 \%$ of cases. Indeed, according to studies, the strabismus encountered in albinism can be explained by abnormalities in the distribution of retino-geniculate and geniculo-cortical visual fibers that hinder the development of binocular vision [6] [14].

Nystagmus

Patients had congenital onset nystagmus in $100 \%$ of cases. This finding is also made by Ebana, Aboubakar and Mokaya [6] [5] [18] who had found a nystagmus in almost $100 \%$ of cases in their series. According to the literature, nystagmus in albinism is almost constant and can be discovered in the first months of life when it is full. It increases with glare and decreases with the use of optical correction [2]. This nystagmus is due to foveal hypoplasia and other ocular abnormalities frequently encountered in albinism [22] [23].

Torticollis

Torticollis in primary fixation by far was noted in $26 \%$ of cases in our series. This figure deviates from that of Ebana, which reported it in $35.7 \%$ of cases [6]. According to studies, most people with albinism adopt a compensatory head posture that reduces nystagmus and improve vision [2]. The morphological variability of the nystagmus describes different types namely horizontal torticollis, vertical or mixed [2] [21].

\section{Iris transillumination}

Iris transillumination was found in all our patients. This finding is also reported by Mokaya and Ebana, who reported iris transillumination in $87 \%$ and $100 \%$ of cases respectively [6] [18]. Indeed, due to melanin deficiency in the stroma and posterior epithelium of the iris, the light reflected by the retina is not filtered and patients with albinism then undergo iris transillumination. The latter can be complete, it is the classic pink eye, not obvious with, in this case a red pupillary reflection visible under certain incidences and sometimes incomplete, only visible to the slit lamp [24].

\section{Amblyopia}

Patients had moderate amblyopia in $88.4 \%$ of cases. Indeed, studies report that albinism is responsible for $5 \%$ to $10 \%$ of the world's low vision [2] [21]. However, amblyopia in the albino subject may be of functional or organic origin 
and the risk of strabismus amblyopia in albinism is low [2] [21].

\section{Foveal hypoplasia}

Foveal hypoplasia was described in $86 \%$ of cases. This result tends towards that of Mokaya [18] which found it in $100 \%$ of the cases. According to studies, patients with albinism have characteristic anatomical deficits such as foveal hypoplasia and the abnormal decussation of the optic fibers [2] [21]. Foveal hypoplasia is probably the most significant limiting factor in albino vision and is thought to be due to a low amount of melanin in the retinal pigment epithelium [25] [26].

\section{Retinal hypopigmentation}

Retinal hypopigmentation was found in $65.1 \%$ of the cases in this series, this result being similar to that of Mokaya [18] who found it in $97.5 \%$ of cases. The poor vision, seen in albinos, is not only due to an absence of pigments that would prevent the formation of a dark room as in a normal eye. Histology shows an atypical retina, containing an abnormally poor fovea in cones. The retina is a neural tissue and the cone and rod receptor cells are in contact with the retinal pigment epithelium [10] [27].

Aspect of the optic disc

The papilla was small and pale in $81.3 \%$ of cases. Papillary morphological abnormalities are frequent and correlated with visual acuity level in albinism. These abnormalities were classified into four stages according to B. Kässmann, in a study of a series of more than 600 patients [28].

\section{Conclusion}

The ocular manifestations found in albinos living in Libreville are similar to those described in studies. They require ophthalmological follow-up or medical and surgical management if necessary. Photophobia exacerbated by astigmatism associated with amblyopia constitutes a real visual handicap by their constant and disabling character for albinos. Albino's refusal to adhere to organized health actions with a retreat on their own would be due to the different mystical-political beliefs encountered in Africa and elsewhere. It would be desirable for the policies to take this statement into account and consider it a real public health problem to facilitate the social and professional integration of all albinos living in Libreville.

\section{Conflicts of Interest}

The authors declare no conflicts of interest regarding the publication of this paper.

\section{References}

[1] King, R.A., Hearing, V.J., Creel, D., et al. (1995) Albinism. In: Scriver, C.R., Beaudet, A.L., Sly, W.S. and Valle, D.V., Eds., The Metabolic and Molecular Basis of Inherited Disease, McGraw-Hill, New York, 4353-4392. 
[2] Rooryck, C., Morice, F., Mortemousque, B., et al. (2007) Le soleil et la peau chez l'enfant: Albinisme. Albinisme oculocutané. Annales de Dermatologie et de Vénéréologie, 45, 55-64.

[3] Hong, E.S., Zabeed, H. and Repacholi, M.H. (2006) Albinism in Africa as Public Health Issue. BMC Public Health, 6, Article No. 212. http://www.biomedcentral.com/1471-2458/6/212

[4] Lee, S.T., Nicholls, R.D., Schnur, R.E., et al. (1994) Diverse Mutations of the P Gene among African-Americans with Type II (Tyrosinase-Positive) Oculocutaneous Albinism (OCA2). Human Molecular Genetics, 3, 2047-2051.

[5] Okoro, A.N. (1975) Albinism in Nigeria. A Clinical and Social Study. The British Journal of Dermatology, 92, 485-492. https://doi.org/10.1111/j.1365-2133.1975.tb03116.x

[6] Ebana Mvogo, C., Bella Hiag, A.L., Ellong, A., et al. (1999) Les troubles visuels de l'albinos. Etude hospitalière réalisée à l'hôpital général de Douala. Cahiers Santé, 9 , 89-91.

[7] Kassir, M. and Dodredingao, D.N. (1998) L'albinisme dans la province du Cameroun: Du diagnostic au conseil génétique. Medecine d’ Afrique Noire, 457-461.

[8] Louis, V. (1872) Sur quatre cas d'albinisme observés au Gabon dans une même famille. Bulletins et Mémoires de la Société d'Anthropologie de Paris, 516-519. https://doi.org/10.3406/bmsap.1872.4514

[9] Gassama, M. (2008) Aspects Epidemio-Cliniques et prise en charge dermatologique des albinos dans le service de dermato-vénéréologie du Cnam (Ex Institut Marchoux). Thèse, Bamako, 24-49.

[10] EL-Ballouti, M. (2004) L'albinisme chez l'enfant. Thèse, Médecine: Rabat, 151 p.

[11] Sauer, A. and Speeg-Schatz, C. (2012) Albinisme oculocutané. Journal Français D' Ophtalmologie, 35, 850-851. https://doi.org/10.1016/j.jfo.2012.01.004

[12] Jeambrun, S.B. (1991) Les formes cliniques et génétiques de l'albinisme. Les Enfants de la Lune (L'albinisme chez les amérindiens). Insern, Paris, 149 p.

[13] Madelain, J. and Turut, P. (1989) Albinisme: Signes, Diagnostic, Traitement. Ophtalmologie en Questions, Lab. Chauvin, 1-20.

[14] Risse, J.F. and Heid, E. (1997) Blancat. Pathologie du revêtement cutanéo-muqueux. In: Flament, J. and Storck, D., Eds., Eil et pathologie générale, Masson, Paris, 764-771.

[15] Aboubakar, H., Dohvoma, V., Ebana Mvogo, S., et al. (2017) Le nystagmus du sujet abinos camerounais. Health Sciences and Diseases, 18, 25-28. http://www.hsd-fmsb.org/

[16] Ajose, F.O., Awosanya, G.O.G., Adekoya, B.J., et al. (2014) Visual Defect in Oculocutaneous Albinism Is Not Associated with Gross Structural Anomaly. Journal of Clinical \& Experimental Dermatology Research, 5, 228. https://doi.org/10.4172/2155-9554.1000228

[17] Gargouri, S., Kaibi, I., Sakka, M., Abid, I., Sallami, D. and Feki, J. (2017) La prise en charge optique des albinos en Tunisie. Refractive management of albinism in Tunisia. J.I.M. Sfax, No. 25, 40-44.

[18] Mokaya, A.K., Njuguna, W., Ilako, D. and Choskey, P. (2014) Pattern of Ocular Findings in Persons with Albinism in Kenya.

[19] Traboulsi, E. and Green, W.R. (2006) An Overview of Albinism and Its Visual System Manifestations. In: Jaeger, W., et al., Eds., Duane's Ophthalmology Edition, 
Chapter 38, Lippincott, Williams and Wilkins, Philadelphia, 60-66.

[20] Duncombe-Poulet, C. (2014) L'albinisme, étiologie fréquente des nystagmus congénitaux.

[21] Kumar, A., Gottlob, I., Mclean, R.J., Thomas, S.M., Mervyn, G., Thomas, M.G., et al. (2011) Clinical and Oculomotor Characteristics of Albinism Compared to FRMD7 Associated Infantile Nystagmus. Investigative Ophthalmology \& Visual Science, 52, 2306-2313. https://doi.org/10.1167/iovs.10-5685

[22] Dijkstal, J.M., Cooley, S.-S., Holleschau, A.M., King, R.A. and Summers, C.G. (2012) Change in Visual Acuity in Albinism in the Early School Years. Journal of Pediatric Ophthalmology and Strabismus, 49, 81-86.

https://doi.org/10.3928/01913913-20110628-02

[23] Summers, C.G. (1996) Vision in Albinism. Transactions of the American Ophthalmological Society, 94, 1095-1155.

[24] Abadi, R.V. and Dickinson, C.M. (1983) Monochromatic Fundus Photography of Human Albinos. Archives of Ophthalmology, 101, 1706-1711.

https://doi.org/10.1001/archopht.1983.01040020708008

[25] Levin, A.V. and Stroh, E. (2011) Albinism for the Busy Clinician. Journal of American Association for Pediatric Ophthalmology and Strabismus, 15, 59-66. https://doi.org/10.1016/j.jaapos.2010.10.012

[26] Naumann, G.O.H., Lecher, W. and Schroeder, W. (2003) Foveal Aplasia in Tyrosinase Positive Oculocutaneous Albinism. Graefes Archive for Clinical and Experimental Ophthalmology, 9-197.

[27] Seo, J.H., Yu, Y.S., Kim, J.H., Choung, H.K., Jang, W., Kim, S.J., et al. (2007) Correlation of Visual Acuity with Foveal Hypoplasia Grading by Optical Coherence Tomography in Albinism. Ophthalmology, 15, 47-51.

https://doi.org/10.1016/j.ophtha.2006.10.054

[28] Kässmann-Keller, B. and Seitz, B. (2007) Phenotype of the Visual System in Oculocutaneous and Ocular Albinism. Ophthalmologe, 104, 648-661. 